\section{Australian budget pleases most researchers}

The Australian biomedical research community, buoyed by an unprecedented boost in funds in the May 11th federal budget, hopes that the government'snewfound commitment to science will be enhanced by changes to the corporate tax regime to encourage investment in biotechnology.

The government exceeded expectations by doubling the budget of thecountry's major grant provider, the National Health and Medical Research Council (NHMRC), in line with the recommendations of the final report of the Wills strate gic review of the research sector released the same day, and announced an array of reforms. By 2005, the NHMRC will be drawing on some AUS\$305 million (US\$203 million) compared with this year's $\$ 170$ million which saw 75 percent of grant applicationsfail (Nature M ed. 5, 9; 1999).

NHMRC research committee chairman Warwick Anderson says the boost will revitalize a demoralized sector by providing a more attractive career structure and halting the 'brain drain' to overseas.

The government stipulated genomics research will be a chief beneficiary of the NHM RC funding boost, and announced a further $\$ 20$ million will be spent on capital works-the first competitive round for capital funding since 1992. In addition, the Commonwealth Scientific and Industrial Research Organisation has been promised an extra $\$ 82$ million over threeyears, and the government sealed its commitment to biotechnology with an $\$ 18$ million investment.

However, Federation of Australian Scientific and Technological Societies president Peter Cullen says that the $\$ 90 \mathrm{mil}-$ lion increase for university infrastructure is still a drop in real terms, leaving laboratories and libraries starved of funds.

Treasury Minister Peter Costello's claim that "no previous Australian Government has ever given health and medical research such a high priority" was echoed by Australian Society for M edical Research president Matt Gillespie, who acknowledged that the government was redressing previous neglect "in an unprecedented manner." Medical research will receive an increase of $\$ 614$ million over six years.

John Shine, president of the Association of Australian Medical Research Institutes, acknowledges the government's "sea-change in attitude" but says the picture won't be complete until industry increases its contribution: "A major issue that still remains to complete the vision of what Wills called The Virtuous Cycle [the title of his report] is reform of the capital gains tax for investment in early stage research."

Peter Wills, chairman of the Garvan Institute of Medical Research, is optimistic that the crippling grip on capital gains will be addressed in a forthcoming review of corporate taxation. "I think we can take comfort from the fact that the government has madesuch a big commitment in this budget and that to have no changes in capital gains tax is fairly unlikely," he told Nature M edicine, adding, "M eanwhile, the budget's big injection of funds will put Australia among thetop 12 research countries in the world."

RADA Rouse, Brisbane

\title{
WMA to revise medical research guidelines
}

A working group established by the World Medical Association (WMA) has been given thetask of preparing revisions to the Declaration of Helsinki, a document originally created in 1964 by international agreement and long cited as a cornerstone of worldwide regulations covering medical research. The revision process, begun at a WMA meeting in Santiago, Chile in April, is still in its infancy, but some observers are al ready criticizing the effort.

The WMA wants to clarify the Declaration'swording on requirements for ethical research: "There are a few terms that in different parts of the world mean different things to different people... that has really caused some major differences in interpretation," says Delon Human, SecretaryGeneral of the WMA.

Robert Levine, Chairman of the Human Investigation Committee at Yale University School of Medicine, and principal author of the changes proposed in Santiago, says some of the flaws are fundamental: "Many of us have known for years that there's a logical error in the Declaration of Helsinki in that it divides research into clinical and non-clinical and establishes separate rules for the two." A strict inter- pretation of the current Declaration, Levine contends, would outlaw most modern medical research. Placebocontrolled drug trials, for example, would be forbidden by the Declaration's stipulation that subjects must stand to benefit from a research project.

In an effort to clarify the guidelines, the WMA, a confederation of the national medical associations of 70 countries headquartered in France, has held meetings to discuss revisions written by individual experts, including Levine. At the April meeting, however, the attendees decided to adopt a new approach, appointing a three-member working group chaired by president of the American Medical Association (AMA), Nancy Dickey, which will collect commentsfrom WMA member associations to develop a new version of the Declaration.

"The bad thing about [the Declaration] is that every time doctors want to do research that the code seems to prohibit, they rewrite it," says George Annas, Professor of Health Law at the Boston University School of Public Health. Annas believes that the current round of revisions is in direct response to the controversy surrounding placebo-controlled HIV drug trials in Africa (Nature Med. 5, 1; 1999). One rumored example of a wording change under consideration involves the Declaration statement, "In any medical study, every patient should be assured of the best proven diagnostic and therapeutic method." This may become, subjects "will not be denied access to the best proven diagnostic, prophylactic or therapeutic method that would otherwise be available to him or her."

But many complain that this wording represents a double standard, a charge that Levinestrongly denies. "Thestandard that we're attempting to develop is the same standard worldwide, and that is you cannot deprive people of treatments that they would otherwise receive," he says, adding that placebo-controlled trials in the developing world are necessary to develop treatments which thosecountries can afford to use.

AMA representatives, who asked not to be quoted, estimate that the revision process will take at least six months and will continue at the next WMA meeting in Tel Aviv, Israel in October. Human adds that "when you ask for comments on a timeless document like the Declaration of Helsinki you really get a spectrum of comments, ranging from no changes to maximal changes."

\section{Alan Dove, New York}

